\title{
P02-45
}

\section{DIAGNOSTIC STABILITY OF MOOD DISORDERS IN A PSYCHIATRY DAY-HOSPITAL}

V. Teixeira de Sousa, J. Marques, A. Martins, I. Domingues, R. Pedrosa, R. Curral, A. Roma Torres

Psychiatry, Hospital de S. João, Porto, Portugal

Mood disorders are common and account for one of the greatest causes of disability worldwide. Accordingly, those conditions are frequent among patients treated in Psychiatry Day-Hospitals facilities. Patients referred for treatment in Hospital de São João DayHospital have a previous variable period of follow-up in ambulatory clinic or hospitalization, commonly, with an established diagnosis. Notwithstanding, during the Day-Hospital stay, diagnosis may be reviewed because of new clinical data. Diagnostic stability over time is an important issue in clinical practice because it may influence treatment and, therefore, the final outcome. It is closely related with the contact between the patient and the healthcare system. Diagnostic instability is commonly due to fluctuation of disease manifestation over time or presence of co-morbid psychiatric illness in combination with rigid diagnostic criteria. The main objective of this study is to evaluate the diagnosis stability of Mood Disorders among patients treated in a Psychiatry Day-Hospital, applying ICD-10. The clinical sample includes patients admitted to Hospital de São João Psychiatry Day-Hospital whose main diagnosis is a Mood Disorder (F30-39), in the period between January 2005 and June 2008. Admission and delivery diagnosis were compared for each patient in this diagnostic category. Results suggest a high level of stability in this diagnostic group in the Day Hospital setting. For global conclusions about stability of Mood Disorders it would be interesting to replicate this study with larger samples and in different settings. 